\title{
Letter to the Editor: Smoking and older age associated with mumps in an outbreak in a group of highly- vaccinated individuals attending a youth club party, the Netherlands, 2012
}

J Hassan (jaythoon.hassan@ucd.ie) ${ }^{1}$, M Carr $^{1}$, J Connell ${ }^{1}$, C De Gascun ${ }^{1}$

1. National Virus Reference Laboratory, University College Dublin, Ireland

Citation style for this article:

Hassan J, Carr M, Connell J, De Gascun C. Letter to the Editor: Smoking and older age associated with mumps in an outbreak in a group of highly-vaccinated individuals attending a youth club party, the Netherlands, 2012 . Euro Surveill. 2014;19(20):pii=20807. Available online: http://www.eurosurveillance.org/ ViewArticle.aspx?Articleld $=20807$

\section{To the Editor:}

In their recent article, Ladbury et al. present an investigation of an outbreak of mumps in a highly vaccinated group attending a youth club party in March 2012 [1]. The article suggested that crowded social events and smoking may facilitate spread of mumps virus among a highly vaccinated population and that waning immunity may also play a role. We would like to address a number of interesting points.

Firstly, the elevated attack rate (AR) of mumps virus among smokers (41.7\%) and non-smokers (15.9\%) and the significantly increased risk ratio (RR) $(3.1 ; 95 \% \mathrm{Cl}$ : 1.6-6.0, $p=0.001)$ attributed to smoking at the youth club party is noteworthy in this highly vaccinated cohort when exposure through saliva transmission and sharing of cigarettes was discounted. Exposure to cigarette smoke is known to be associated with a significant increase in the risk of important bacterial and viral respiratory infections. Smokers incur an up to fourfold increased risk of invasive pneumococcal disease and influenza incidence and clinical severity is higher in smokers compared to non-smokers [2]. In vitro, cigarette smoke extracts suppress anti-viral and innate immune responses following infection by respiratory RNA viruses including the respiratory syncytial virus which is a paramyxovirus highly related to mumps virus $[3,4]$. Allied with waning immunity to mumps this could potentially contribute to the increased susceptibility of subjects' infection and account for the apparent higher attack rates.

Secondly, the authors reported that another independent risk factor for mumps infection was older age. Respondents aged $\geq 21$ years had a significantly higher AR (54.6\%) than those under 21 (14.9\%, (RR 3.7; 95\% Cl: $1.5-8.7, p=0.005)$. A report from Australia in 2007 identified $76 \%$ of mumps notifications as people aged 20 years or older [5], and we have also reported similar findings in two separate mumps outbreaks in highly vaccinated populations in Ireland [6, 7]. Indeed, in the years between outbreaks, mumps cases were highest in persons' $\geq 30$ years of age, suggesting that this may be the cohort maintaining ongoing mumps transmission; however, the mechanisms of continued transmission remain unclear and warrant further study.

Thirdly, the possibility of incomplete humoral protection or waning immunity following mumps vaccination or natural infection suggests that the presence of mumps-specific IgG antibody levels may not prevent re-infection. However, based on the mild clinical symptoms observed by Ladbury et al., one could argue that the response to the vaccine had a clinically protective effect following exposure to the virus. Thus, it is probable also that the viral load in the respiratory tract of these individuals would be significantly lower than that during primary mumps infection, and the risk of onward transmission would be low.

\section{References}

1. Ladbury G, Ostendorf S, Waegemaekers T, van Binnendijk $\mathrm{R}$, Boot $\mathrm{H}$, Hahné S. Smoking and older age associated with mumps in an outbreak in a group of highly-vaccinated individuals attending a youth club party, the Netherlands, 2012 . Euro Surveill. 2014;19(16):pii=20776.

2. Arcavi L, Benowitz NL. Cigarette smoking and infection. Arch Intern Med. 2004;164(20):2206-16. Epub 2004/11/10.

3. Eddleston J, Lee RU, Doerner AM, Herschbach J, Zuraw $B L$. Cigarette smoke decreases innate responses of epithelial cells to rhinovirus infection. Am I Respir Cel Mol Biol. 2011;44(1):118-26. http://dx.doi.org/10.1165/ rcmb.2009-02660C

4. Modestou MA, Manzel LJ, El-Mahdy S, Look DC. Inhibition of IFN-gamma-dependent antiviral airway epithelial defense by cigarette smoke. Respir Res. 2010;11:64. http://dx.doi. org/10.1186/1465-9921-11-64

5. Senanayake SN. Mumps: a resurgent disease with protean manifestations. Med J Aust. 2008;189(8):456-9.

6. Carr MJ, Moss E, Waters A, Dean J, Jin L, Coughlan S, et al. Molecular epidemiological evaluation of the recent resurgence in mumps virus infections in Ireland. J Clin Microbiol. 2010;48(9):3288-94. http://dx.doi.org/10.1128/JCM.00434-10

7. Hassan J, Dean J, Moss E, Carr MJ, Hall WW, Connell J. Seroepidemiology of the recent mumps virus outbreaks in Ireland. J Clin Virol. 2012;53(4):320-4. http://dx.doi. org/10.1016/j.jcv.2011.12.022 